\title{
7
}

\section{Case study of the Information Systems Strategy (ISS) of the Hong Kong Education Department}

\author{
S.H. Hsu \\ Education Department, 14/F Wu Chung House, \\ 213 Queen's Road East, Wan Chai, Hong Kong
}

\begin{abstract}
To improve the efficiency and effectiveness of Hong Kong education, the Education Department has embarked on an Information Systems Strategy (ISS). Under this five-year strategy, Information Technology will be employed to develop an integrated computer network linking the department and over 1,500 public sector primary and secondary schools. On implementation of this 70 million US dollars project, much of the manpower and resources currently engaged in information processing will be saved. Furthermore, the information infrastructure will provide the strategic information necessary for policy making, putting the department in a better position to meet the challenges of the 21 st century.
\end{abstract}

Keyword Codes: H.4.0; H.2.8; H.5.3

Keywords: Information Systems, General; Database Applications; Information Interfaces

\section{BACKGROUND}

Education has been one of the top priorities of the Hong Kong Government. Given our lack of natural resources, maintaining a highly educated work force is the best investment to ensure that our economy would continue to thrive and remain vibrant to meet the challenges of the years ahead.

Against the backdrop of years of economic development and an increasingly open government, the last decade has seen rapid changes in our education system. As the education services become more sophisticated and the focus shifts towards the quality aspects in education, school administration and management have become more complex. Concern has been repeatedly voiced that, while coping with day to day administration, teachers are spending less time in teaching activities, pastoral care for individual students and their own professional development.

In tandem, the demand for information to support various management functions is ever rising. This trend coupled with the evolution of the society towards a more participative governance, has imposed a heavy demand on managers for information. Pressure is not only felt by the administrators who are accountable to the legislature for resources they control, teachers and school authorities have also been required to contribute data and information from their predominantly manual records for collation by traditional means.

To cope with such changes, Information Technology (IT) has been used in some schools and the Education Department (ED) to support their routine operational, administrative and management processes. However, the use of IT in such a piecemeal manner has serious limitations. 
At the school end, we find pockets of computer expertise which drives an uneven pace of change. Some schools have had years of computerisation experience and developed sophisticated applications on very powerful platforms, while other less well endowed establishments still rely heavily on clerical procedures to carry out daily routines.

The same is true for the Education Department. Moreover, as much business is transacted among sections within ED, the fragmented approach has resulted in duplication and inconsistency of data. More unsatisfactory is the fact that almost all transactions between schools and ED have to be carried out through the use of paper documents, the source of which information could well be already resident in computers to some extent. This clearly represents an inefficient utilisation of the human resources.

\section{CONSULTANCY STUDY}

Concurrent with these developments, the Hong Kong Government has been actively pursuing reforms in its management procedures with the aim of improving efficiency and providing better service to the public with the resources available. Like all governments, the Hong Kong administration is constantly facing difficult choices in satisfying a myriad of wants spread over a wide range of social services. Following a high level review, the Hong Kong Government embarked on the Public Sector Reform in 1989. The salient principle of the reform is to establish a closer match between resource responsibilities and management responsibilities.

Taking the reform to the Schools Education Programme, ED introduced in March 1989 "The School Management Initiative - Setting the framework for quality in Hong Kong schools". This document set out plans and strategy for achievement of quality education through enhanced management procedures within all public sector schools. The intention of the policy was that management roles would be better defined, resource responsibilities and management responsibilities would be more aligned and schools would be enjoying a greater degree of autonomy in their own administration and resource control. In short, "more management and less administration" is the spirit of the initiative.

As the whole system becomes more decentralised, there is a dire need for improved information capabilities in order to support decisions at various levels. In recognition of this, a consultancy firm was engaged by the Hong Kong Government at the end of 1991 to conduct a study into the information needs of the school education programme. Based on the strategic direction and objectives of the school education programme and the current degree of computer use, the consultants gave their objective assessments on the information requirements of the school education programme, and some initial views about opportunities for using IT within it.

Referring to these recommendations, the consultants then engaged in a follow-up study to review and examine the strategic options available to meet the information needs of the school education programme. The options considered related to a portfolio of applications that Government should consider implementing over the next five years and the technical and organisational infrastructure that would be required to support them.

As a result, the consultants recommended the implementation of an Information Systems Strategy (ISS). Initially, they identified sixteen application portfolios, some targeting the improvement to operational efficiency while others involved the provision of an informed basis for planning or decision making. Obviously, the financial implications for developing such a whole- 
scale integrated system were expected to be enormous by any standards. Considering the level of resources required, the risk of failure, and the impact on the organisation, the consultants thus recommended a set of core applications that would ensure that ED can respond to policy imperatives, build a flexible infrastructure for the future and undertake a manageable project load.

The strategy, in brief, consists of applications built on a three-tier model using the client-server approach. They would link all schools to the district education offices which in turn are connected to the ED headquarters. The hardware to support the applications portfolio comprises a number of components such as a mainframe computer at the headquarters, a number of mid-range computers located at the district education offices, and a local area network at schools. The technical framework to support the application portfolio should be designed on the basis of key principles such as ease of use, effectiveness, efficiency, and flexibility.

The consultants envisaged that the most important benefit to the people of Hong Kong from Government investment in the ISS would be in the substantial amount of extra time that teaching staff would be able to devote to individual students both in learning tasks and with personal problems and issues. This would not only make a significant contribution to the prosperity and well-being of Hong Kong in the medium to long term by raising the skills, abilities and awareness of the population, but may immediately help avert some of the more drastic consequences of the currently intensely competitive nature of education. These substantial gains, achieved by relieving teaching staff of many of the routine administrative tasks that take up so much of their time, would be equivalent to an additional 1,400 man-years of additional teacher effort per year.

At the same time there would be significant improvements in the efficiency and effectiveness of administering the educational services, which, in turn, would free resources and give taxpayers more value for money. Additionally, facilities in these applications would be critical for the implementation of a series of new policy initiatives, which require considerable information support.

In April 1993, the Government accepted the recommendations. Then in September 1993, the ISS was given the green light to proceed at an estimated cost of 70 million US dollars over a period of five years.

\section{SCOPE OF THE INFORMATION SYSTEMS STRATEGY}

The ISS is basically a large scale computerisation project consisting of the following nine major components and two supporting projects:-

School Administration and Management System - a computerised information system for schools to support management, planning and administration;

Integrated Student and School Applications - a set of core databases of students and schools, and a revamped computer system to support allocation of school places at key levels;

Teacher Information Management System - a core database of teachers, to support various kinds of processing such as teacher registration;

Office Systems - computing facilities for data transfer and internal communication; 
Financial Management and Budgeting - functions to support financial management of resources;

Forecasting, Planning and Statistical Tools - provision of software tools for planning and analysis purposes;

Management Information System - provision of software tools to support decision making by senior management;

Initial Curriculum Resource Enquiry - a database accessible to teachers containing basic index and synopsis of curriculum resources as an initial measure to facilitate efficient use of curriculum material;

Pilot Geographical Information Management - a pilot to evaluate the use of digital storage of graphical data such as school building plans;

Data Standardisation and Administration - identification of corporate data model and standardisation of data items; and

Technical Infrastructure - project to handle the technical aspects of the other component projects in the ISS.

\section{IMPLICATIONS}

The integrated approach to computerisation in our school education programme will result in a variety of benefits, some of which are described below.

Teachers will be relieved of many of the routine administrative tasks. The effort thus saved will enable teachers to devote more of their time to individual students both in learning tasks and in dealing with personal problems and issues. With better access to audio-visual and curriculum resource material, the quality of classroom teaching will also improve.

By extension, students will receive more attention from teachers. Timely assistance and guidance can be provided to those students in need. With the help of the computer, parents will find it easier to locate a suitable school place for their child. Members of the public will also enjoy a better enquiry service because, with the provision of on-line access to territory-wide information kept in the central databases, a "one-stop" service to clients can be provided.

The management information system will save a substantial amount of clerical effort on routine administration work. With better information support, schools will become more efficient in planning and managing their human and financial resources. The markedly improved communications with ED and the storage of key data in core databases will greatly facilitate enquiries related to teacher appointment, application procedures and education regulations.

In implementing the ISS, substantial improvement in the education services can be expected. The existing ageing operational systems will be replaced or re-engineered to converge with the information processing backbone. The new systems will be easier to use, less expensive to 
maintain, but more powerful in application. Transactions between schools and ED will be more direct and efficient, while paper flows will be significantly reduced, thus alleviating the manual collation and checking of necessary data and minimising the huge duplication of data on schools, teachers and students.

The ISS will also equip ED with a corporate database which will hold comprehensive, consistent and readily accessible information on schools, teachers and students. This, together with much greater computing power, will largely enhance strategic planning and effective deployment of resources.

The activities in the development cycle will also help all officers to focus on the informational aspects in operation, preparing them for the information explosion ushered in by the revolution in telecommunication. At the corporate level, the exercise will help to build up an organisation structure that can perpetuate the review orientation without which no organisation can hope to survive in this fast evolving world.

\section{MAJOR ISSUES}

While the above vision is highly optimistic, we have no illusion that the passage will be plain sailing. The following analysis will reveal some of our concerns.

The Hong Kong education system has evolved over a long period of time, drawing its traditions from both the East and the West. Thus there is extremely considerable diversity in schools and the whole system has become extremely complex. To take a few examples, we see vastly different types of curriculum being offered, many different modes of funding arrangements, and markedly different timetable structures. Whereas diversity and choice may be advantageous under open market conditions, this situation presents difficulties when data items need to be standardised at a corporate level. The system is further complicated by the fact that we have two official languages, English and Chinese, which are used in all formal correspondence and information exchanges. While computer processing in English is commonplace, the processing of information in Chinese has yet to be standardised.

The information system aims at providing an electronic linkage for no less than 1,500 schools. Its sheer size is a pioneering effort for Hong Kong. Unfortunately, we do not have the benefit of drawing from experience overseas. The tasks ahead will be particularly difficult once the system is fully integrated and requires the use of state-of-the-art approaches in some areas.

The implementation of ISS requires, in many instances, the redefining of roles and responsibilities for various users within the education system. Old procedures would have to be reengineered and new ones set up to dovetail with the computer system operation. This would inevitably lead to pervasive changes in the practices and structure of both schools and ED. Understandably, there will be those who find the changes threatening and this could be the cause for some degree of resistance.

On the technical front, the scale of ISS has introduced issues for which difficult decisions will have to be made. A typical example is whether to centralise hardware and operators, distribute operators, or distribute both. The choice of technical options is further complicated by the number of small, remote schools, scattered all over the territory, where electronic linkage is limited and computer expertise may be non-existent. 


\section{MEASURES TO ENSURE SUCCESS}

To address some of the above problems and to meet the challenges of the undertaking, a phased approach to implementation has been adopted whereby the system will be rolled out in batches to the smaller groups of users. This will hopefully achieve a smooth transition and help to contain teething problems.

To guarantee that the future system meet the needs of users at the school level, a "partnership" approach has been adopted where practising teachers and serving principals are actively involved during implementation. In pursuit of this objective, a number of briefings, seminars, interactive workshops and user brainstorming discussions have been held. Moreover, serving teachers and principals have been seconded to work closely with system engineers in the actual design work.

To improve user acceptance, the system will be designed with particular attention to userinterface techniques and the choice of software tools. Hopefully, the system will be user-friendly, even to novice users of IT.

Furthermore, pilots are being conducted in schools where prototypes are tested in an operational environment and the evaluation findings will serve as the basis of improvement. In the same vein, advanced technology will be piloted, until technology has proven records of success, before wider application at the school level.

Training is another pivotal point in development. A variety of programmes bundled in flexible and easy-to-use packages are being developed, which cater for the wide spectrum of trainees.

\section{CONCLUSION}

The above paragraphs have described the anticipated development of the ISS project in the next five years. We strongly believe that the informational infrastructure, harnessing IT for educational use, will become a vital part of our education system that could help teaching professional to keep up with the times.

During the gestation stage of ISS, we have sent officers overseas to look at similar integrated systems. Constrained by resources, these visits were necessarily limited. Thus we are setting our sight on further fact-finding visits in the near future.

The ITEM conference offers a welcome opportunity for contact with IT experts in the field of education. Hopefully, we shall be able to build the bridges to allow a free flow of ideas to help us meet the challenges as we move towards the 21 st century. 